\title{
Application of Regional Cultural Elements in the Design of Wenbo Culture Product*
}

\author{
Haibin Dong \\ Xi'an University of Technologya \\ Xi'an, China 710054
}

\author{
Zhuang Hao \\ Xi'an University of Technology \\ Xi'an, China 710054
}

\begin{abstract}
The paper aims to explore an innovative design method which conforms to the aesthetic way and ideology of modern social life and provides satisfaction in tourism consumption from the perspective of regional culture elements. It explains the significance of Wenbo culture product design based on regional culture elements and characteristic elements of library collections and analyzes the roles regional cultural elements and library collections play in Wenbo culture product design, proposing that we should carry out Wenbo culture product design from three aspects as follows: combination of regional and library collections elements extraction, integration of uniqueness, interestingness and contemporaneity, and combination of practicability, story and commemorative significance. The paper takes cultural and creative products in Shaanxi History Museum and dolls of Tang style designed by the author as examples to conduct research and analysis.
\end{abstract}

Keywords-regional culture element; Wenbo culture product; Shaanxi elements; Tang Niu

\section{INTRODUCTION}

Regional culture elements reflect people's thinking and behavior pattern in a certain space-time and area and they come into being through a long period of gradual accumulation, including spiritual, material, institutional, conceptual and cultural level etc. with major performance in tangible and intangible culture. [1] Each area has its own unique traditional and cultural features as historical accumulation and creation of mankind and sources of current design and innovation.

Wenbo culture products are distinctive, including tourist souvenir, cartoon game, cartoon images of major museums, audio and video products and other series of products with culture creativity, and regional culture, library collections and national features. They are commemorative presents to each other with culture creativity and special commodities of historical significance.

Kan Tai-keung, a famous designer, once said, "Culture, design and creativity, the three things, are inseparable. Culture is the essence of life containing creativity; design reflects life and can't do without creativity and culture." [2] Only by designing based on the aesthetic way favored by the mass with cultural connotation and creativity, can good cultural and creative products appear, reflect regional culture and form

*Fund program: Mass Innovation Space and Entrepreneurship Research and Development Project of Department of Science and Technology, Shaanxi Province - Culture Brand Image Product Development(2016ZCKJ3-044). brand features.

Regional culture elements play a key role in innovative design of Wenbo culture products. We should extract regional characteristic elements with reference to modern design concept and technical means and conduct integration in product design to obtain culture innovative products with regional and library collections features which inherit and carry forward regional distinctive culture. Thus, we establish museum brands and enrich the cultural connotation of tourism product.

Analysis on applications of regional culture elements and library collections in innovative design of Wenbo culture products can be conducted in the following aspects:

\section{COMBINATION OF REGIONAL ELEMENTS AND PRESERVED RELICS}

Design through combination of regional elements and extraction of preserved relics transforms regional culture in life into Wenbo culture products or commodities. Compared with ordinary souvenir, culture innovative products with distinctive regional features can display regional and cultural information in a stronger and more straightforward way. Wenbo culture products have specific functions and carry cultural meanings. Priorities are given to commemorative significance and cultural creativity in people-oriented design, which starts from consumers' demand and fully embodies the concept of humanization design. As the image of a city or a scenic spot, Wenbo culture products spread the culture and establish their own brand at the same time. However, most tourist souvenirs are developed by some organizations following their own bent without distinctive regional elements and features of library collections and they are just a copy of souvenirs on sale in tourist attractions of other cities or a scaled-down version of cultural relics in scenic spots. The mainstream products are local specialties and handiwork, including tourist commodities printed with names of scenic spots and scenes, modeling of historical relics and ornaments without any change in carrier. On the contrary, we can hardly see real Wenbo culture products due to lack of culture innovative product design based on tourists' demand. [3] Driven by interests, various kinds of souvenirs are knock-offs with rough craftsmanship in single forms and vulgar images and without regional or library collection features, flooding tourism souvenir products industry. Thus, the vicious circle greatly blocks development of innovative design in Wenbo culture products. It is impossible to rely on Wenbo culture products without independent 
development and humanization design to establish a strong brand and to arouse tourists' interest.

We can endow architecture, figures, implements, pictures, colors and library collections with specific visual signs through summarization, abstraction, extraction, exaggeration, transformation and so on and use these visual signs in Wenbo culture product design smartly. [4] At present, Shaanxi History Museum takes the lead in development of Wenbo culture products and culture innovative products based on museum collections constantly come into the public view. Among culture products attracting tourists in Shaanxi History Museum, there is the cute "Tang Niu" "Fig. 1", a new spokesperson. Daily living equipment such as baggage tag, refrigerator magnet, bookmark and bolster becomes cute with steamed face and star eyes of "Tang Niu" "Fig. 2". Tang Niu's design prototype is a pastel figurine of Tang Dynasty in Shaanxi History Museum, which lacks appetency as an antiquity. Therefore, Xi'an Qiaohe Animation Technology Co., Ltd and Shaanxi History Museum make joint efforts in innovative transformation of the lady figurine as spokesperson of Shaanxi History Museum in a brand new way. Retaining the original cute modeling features and costume features of the lady figurine, Tang Niu is designed through lovely animation and Q-version techniques, which is in line with people's aesthetics. Since the animation image boasts a face and five sense organs with distinctive features of Tang Dynasty, it is named "Tang Niu". As a cartoon image of ancient beauty, "Tang Niu" spreads Chang'an and Shaanxi culture and enhances the brand of Shaanxi History Museum at the same time.

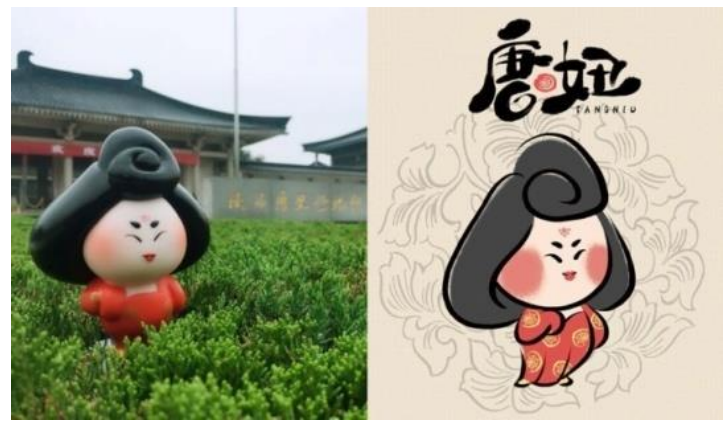

Fig. 1. Tang Niu.

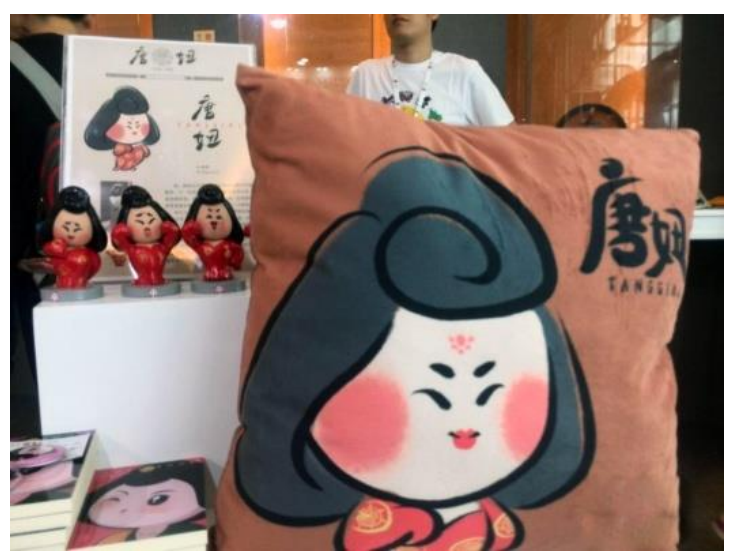

Fig. 2. Tang Niu Bolster.

\section{INTEGRATION OF UNIQUENESS, INTERESTINGNESS AND CONTEMPORANEITY}

Only by adhering to the research and development concept as follows: combining traditional culture with fashion, modern elements and modern crafts, application of novel design and manufacturing means in line with modern aesthetic orientation, using inspiration and stories to express regional culture and the unique cultural connotation of library collections and devotion to design of unique and interesting culture innovative products, can we develop many Wenbo culture products conforming to modern society's aesthetic concept and satisfying people's consumption demand with great influence. If conditions allowed, tourists can be allowed to do it themselves. Filed printing of real Wenbo culture products can be provided through modern 3D printing technology and tourists can follow their own bent in matching colors, thus the working process of Wenbo culture product is endowed with uniqueness, interestingness and interactivity. We believe tourists would love it.

For example, the author works out cute lady dolls based on several ancient beauty images in Hairpin Ladies by Zhou Fang "Fig. 3" with features of modern popular Q-version cartoon characters, whose body proportion is $1: 1$. Since plump ladies in Tang Dynasty are regarded as beauty, the dolls boast squabby round faces. The Q-version image has a blurred physical structure, oval on the whole. The series of lady dolls of Tang style refer to hair style, facial makeup and costume features of ladies in Tang Dynasty "Fig. 4". Tourists can use the data and material provided by the scenic spot to design or make dolls in a customized way and the real product can be obtained through print production of various materials with 3D printing technology, thus making the price flexible. But it doesn't mean that the cheaper the product is, the more likely tourists are to buy. Good characteristic Wenbo culture products can have a high price, because they contain traditional culture and have unique design cost, which is desired most by tourists during the journey because it can bring them unique memory.

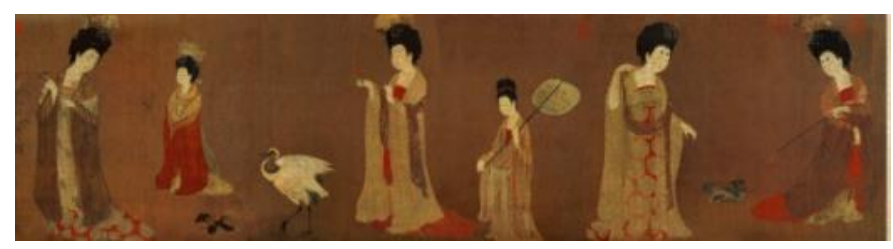

Fig. 3. Hairpin Ladies.

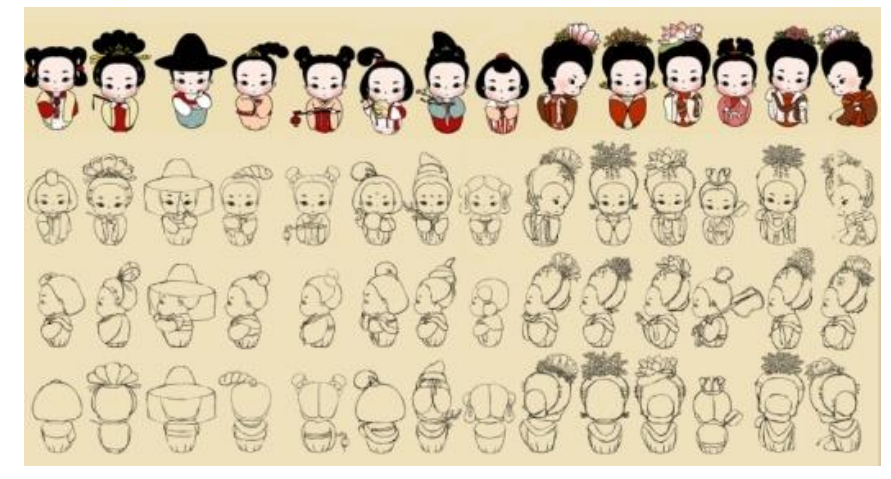

Fig. 4. Series of Dolls in Tang Style. 


\section{COMBINATION OF PRACTICABILITY, STORY AND COMMEMORATE SIGNIFICANCE}

It endows Wenbo culture products with high added value and significance to combine practicability, story and commemorate significance in design of culture products. Tang Niu, based on various modeling of lady figurine collections of Tang Dynasty, is the spokesperson of prosperous Tang culture in cartoon image with elegant standing posture, graceful figure and perfect combination of light and thin dress and plump posture, fully showing grace and gentleness in female of Tang Dynasty. Printed on various carriers, these cartoon babies are dignified, restrained, graceful and noble with rich expressions, plump and smooth-skinned faces, slightly narrowed eyes and slightly opened red lips, bringing pleasure to tourists and boasting ornamental value and practicability. Besides, they endow museum collections with new life and realize the good wish of "bringing the museum home".

$\mathrm{Xi}^{\prime}$ an is the starting point of the ancient Silk Road. Absorbing culture of Tang Dynasty and combining modern people's aesthetics, Tang Niu comes into being as the epitome of the period of great prosperity in Tang Dynasty and the most distinct example of integration of the past and present. The "Searching for Shaanxi elements in the Silk Road" activity participated in by 12 network media re-interprets and redevelops the tradition with modern techniques and Tang Niu happens to have the same view with it. Traditional culture elements inevitably leave a rigid impression on people at ordinary times. People like Tang Niu because she demonstrates distinctive features of Tang Dynasty. As a gift from Xi'an, we can send Tang Niu puppets to scenic spots along the Silk Road and people would love it. In order to achieve diversification in Tang Niu's image, Tang Niu studio and China Network make joint efforts in producing Tang Niu diary, whose whole course is followed in the form of cartoon "Fig. 5" and "Fig. 6". By adding cartoon, news report becomes livelier and more abundant in content, enhancing its commemorative significance. Through the re-tracing the Silk Road activity, "Tang Niu" brings better combination of Chang'an, Chinese and foreign culture and spreads Shaanxi regional elements to the whole world.

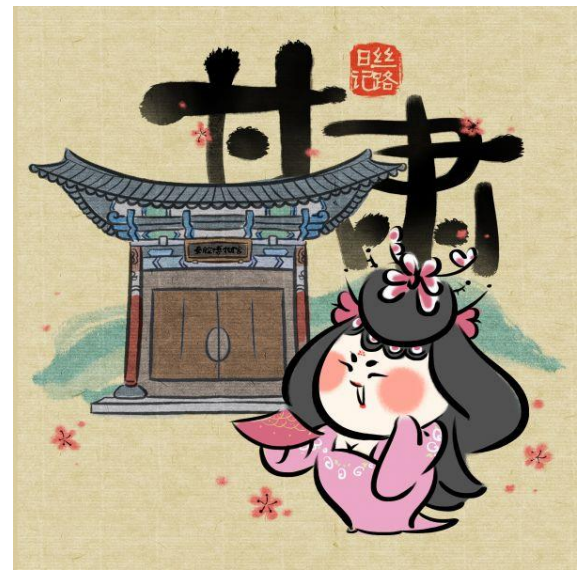

Fig. 5. Tang Niu Comic Diary - Gansu.

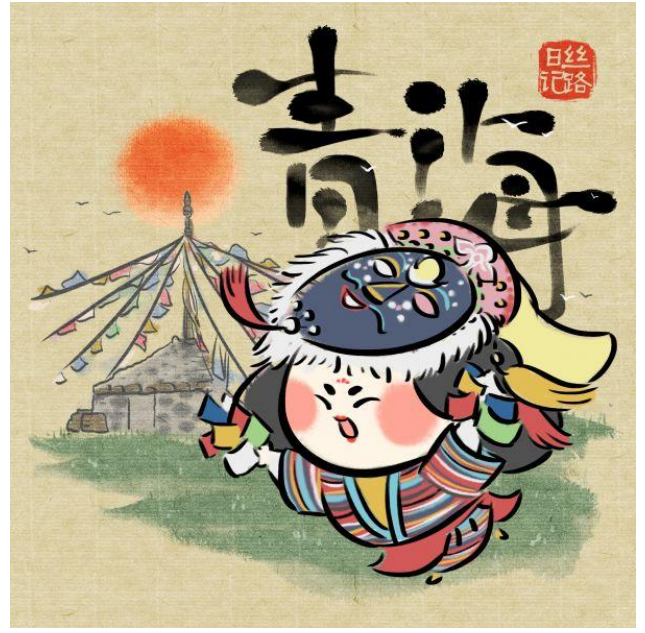

Fig. 6. Tang Niu Comic Diary - Qinghai.

\section{CONCLUSION}

As a kind of special tourist commodity, Wenbo culture product should fully reflect local historical and cultural features and library collection features in terms of design and development. The more local features it has, the more representative it would be. If Wenbo culture products can fully reflect historical and cultural features of local area and cultural relics, it would be easier for tourists to accept them, thus extending museums' distinctive cultural inheritance function. "Exquisite stones can sing" and good Wenbo culture products can "talk". Some products can reflect people's internal feelings and some can communicate with people.[5] Based on regional historical and cultural and preserved-relics' features and in combination with modern design techniques, Wenbo culture commodity system containing regional culture elements with great varieties, and distinctive and competitive brand features is the continuity of tradition and extension of modern times.

\section{REFERENCES}

[1] Duan Jinjuan: a preliminary study on the teaching methods of public facilities design based on regional cultural elements [J] "design art research" [J]., 2011.4117-121

[2] Wang Lili: cultural and creative product design -- a case study of tourism souvenir design. "Popular literature and art" [J], 2012.5, 59-60

[3] Side Kun, Yang Yang, Yang Yang: the regional characteristics of the cultural elements of the extraction and tourism product design methods to explore. "Packaging project" [J], 2012.2130-132

[4] Ye Dehui: Study on the regional cultural characteristics in the design of tourism products. "Packaging project" [J], 2011.8134-137

[5] http://cnews.chinadaily.com.cn/2016-05/22/content_25406531.htm : A more fair heart, China daily, 2016.5 